\title{
Universal thermal climate index (UTCI) and synoptic circulation patterns over the metropolitan city of Athens, Greece
}

\author{
Katavoutas G.* and Flocas H.A. \\ Section of Environmental Physics-Meteorology, Department of Physics, National and Kapodistrian University of Athens, University \\ Campus, Building PHYS-5, 15784 Athens, Greece \\ Received: 20/12/2017, Accepted: 31/07/2018, Available online: 26/09/2018 \\ *to whom all correspondence should be addressed: email: geokat@phys.uoa.gr \\ https://doi.org/10.30955/gnj.002556
}

\begin{abstract}
The present study aims to investigate the human thermal stress with respect to the synoptic scale circulation over the metropolitan city of Athens in Greece. The Universal Thermal Climate Index (UTCI) was applied in order to assess the levels of thermal stress employing three-hour meteorological data for four stations of the urban complex for a ten-year period (2006-2015). The patterns of the synoptic atmospheric circulation were classified in eight distinct categories based on a clustering scheme. The obtained results in summer reveal low UTCI values on days that are associated with a cyclonic pattern or a cold advection from the northwest or north. On the contrary, the days with an anticyclonic pattern show high UTCI values. During winter, low UTCI values are observed on days that are associated with a pure cyclonic pattern, a prevailing northern flow and a strong cold air advection from the northwest or north. During nighttime, high UTCI values are noted on days with south-westerly flow. However, this is not observed during daytime and especially around midday. The analysis also shows that the position of the station affects the levels of thermal stress for the same synoptic category.
\end{abstract}

Keywords: Athens, synoptic classification, synoptic scale circulation, thermal comfort, thermal stress, UTCI

\section{Introduction}

A great number of thermal indices have been developed worldwide in order to assess the impact of thermal environment on human beings in terms of thermal comfort and thermal stress. Among these thermal indices, others are more simplistic and empirical while others are more rational based on human energy balance principles. A few years ago the concept of a thermal index for the assessment of outdoor thermal environment as an international standard drove a multi-disciplinary group of scientists within COST Action 730 on the development of UTCI (Jendritzky et al., 2012). The UTCI assesses the level of thermal stress that the human being is exposed to and it is expressed as an equivalent temperature. Since UTCI takes into account all parameters of human heat balance can be applicable in all climates and spatial scales (Jendritzky et al., 2012). In addition, UTCl scores highly compared to other indices in criteria such as comprehensiveness, scope, sophistication, transparency and validity but it scores lower in usability (De Freitas and Grigorieva, 2017). The sensitivity analyses have shown that UTCl is very sensitive to changes in all meteorological stimuli (Blazejczyk et al., 2012) and especially in wind speed (Provençal et al., 2016), although in hot weather UTCI does not frequently reach high values.

The impact of thermal environment on human beings in terms of the UTCI and other thermal indices has been investigated in different climates and regions as well as in different spatial and temporal scales (Bartzokas et al., 2013; Bröde et al., 2012a; Katavoutas et al., 2015; Lai et al., 2016). Other studies investigate possible associations between thermal indices and human mortality (Nastos and Matzarakis, 2012; Urban and Kyselý, 2014). There are also studies in which the thermal stress levels are analyzed during heat and cold waves (Basarin et al., 2016; Matzarakis and Nastos, 2011; Mavrakis et al., 2012; Theoharatos et al., 2010).

Synoptic weather conditions have a controlling effect on local meteorological conditions of a specific area. Therefore, classifications of the synoptic atmospheric circulation could be valuable research tools in various environmental problems. Kassomenos et al. $(1998,2003)$ developed synoptic atmospheric circulation classification schemes over the greater Athens area in Greece. These clustering schemes have been applied in several studies investigating the relative risk for mortality (Kassomenos et al., 2001; Kassomenos et al., 2007), the urban heat island (Mihalakakou et al., 2002) and the air pollution episodes (Petrakakis et al., 2006). On the contrary, studies investigating the human thermal stress with respect to the atmospheric circulation are relatively scarce (Bartoszek et al., 2017; Kolendowicz et al., 2017; Rozbicka and Rozbicki, 2017). For the metropolitan city of Athens, the connection between thermal discomfort and atmospheric circulation has only been studied during the warm period of the year at 12:00 UTC in terms of the Predicted Mean Vote (Bartzokas et al., 2013). 
The aim of this study is to investigate the seasonal and diurnal variations of the thermal stress levels in the urban complex of Athens based on UTCl with respect to the prevailing synoptic scale circulation for the period 20062015 employing the scheme developed by Kassomenos et al. (1998).

\section{Materials and Methods}

\subsection{Study area and meteorological data}

The metropolitan city of Athens is located in the Attica region and stands among the first eight most populated functional urban areas in the European Union. The Greater Athens Area (GAA) is situated on a basin confined by the mountains Aigaleo, Parnitha, Penteli and Hymettus and faces the Saronic Gulf to the south (Figure 1). The GAA encompasses a total area of $412 \mathrm{~km}^{2}$ with a resident population of about 3.1 million. Athens has an interior Mediterranean climate, mild, with dry and hot summer, which is classified as Csa according to the Köppen-Geiger climate classification. According to the climatic records of the National Observatory of Athens for the station located in the city center, the annual mean air temperature is $17.7^{\circ} \mathrm{C}$ with monthly mean values range from $9.3^{\circ} \mathrm{C}$ in January to $27.0^{\circ} \mathrm{C}$ in July, and the mean annual rainfall is $378 \mathrm{~mm}$.

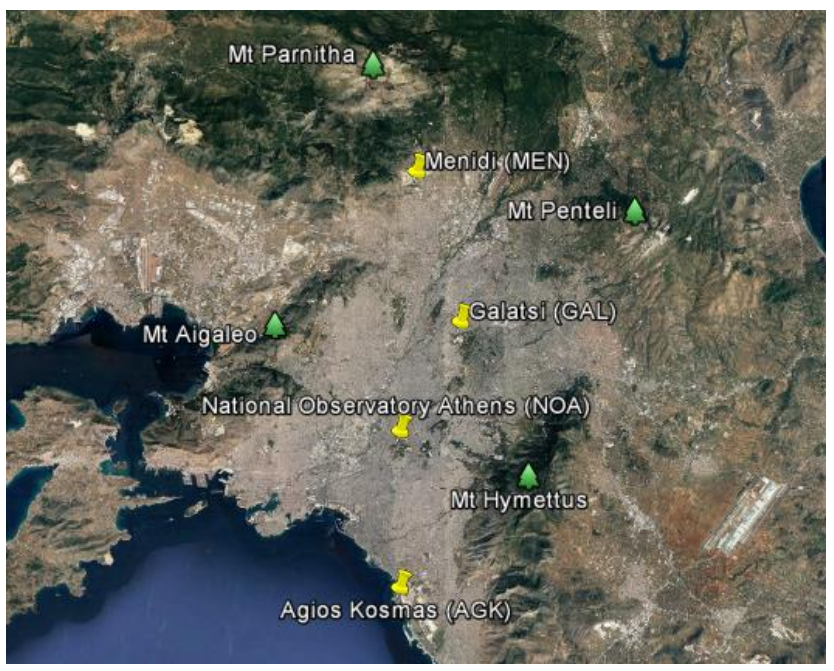

Figure 1. The city of Athens and the location of the stations

Four stations spread across the GAA were considered (Table 1). The Agios Kosmas station (AGK) is located in a suburban area, very close to the seashore and with lowrise buildings. The station of the National Observatory of Athens (NOA) is situated on a hill at the core of the urban area. The third station is installed inside a park at the Galatsi neighbourhood (GAL), a dense urban area with high-rise buildings and high traffic density. The Menidi station (MEN) is located at the north boundaries of the GAA on the foot of mountain Parnitha, an area with lowrise buildings. The three-hour meteorological data of air temperature (Ta), relative humidity ( $\mathrm{rh}$ ), wind speed (v) and global solar radiation (sr) were used, covering a tenyear period (2006-2015) for the aforementioned stations.
Table 1. Physical characteristics of the meteorological stations in the GAA

\begin{tabular}{cccc}
\hline Station & Longitude & Latitude & Altitude (m) \\
\hline $\begin{array}{c}\text { Agios Kosmas } \\
\text { (AGK) }\end{array}$ & $23^{\circ} 43^{\prime}$ & $37^{\circ} 52^{\prime}$ & 6 \\
\hline $\begin{array}{c}\text { National } \\
\text { Observatory of } \\
\text { Athens (NOA) }\end{array}$ & $23^{\circ} 43^{\prime}$ & $37^{\circ} 58^{\prime}$ & 107 \\
\hline Galatsi (GAL) & $23^{\circ} 45^{\prime}$ & $38^{\circ} 01^{\prime}$ & 176 \\
\hline Menidi (MEN) & $23^{\circ} 43^{\prime}$ & $38^{\circ} 06^{\prime}$ & 248 \\
\hline
\end{tabular}

\subsection{Universal thermal climate index}

A few years ago the concept of a thermal index for the assessment of outdoor thermal environment as an international standard drove a multi-disciplinary group of scientists within COST Action 730 on the development of UTCI. The UTCl is based on an advanced multi-node dynamic model of human thermal physiology and comfort (Fiala et al., 2012) and it is coupled with a clothing model in order to determine the clothing insulation based on both ambient temperature and people's clothing behavior (Havenith et al., 2012). The outcome is expressed as an equivalent temperature of the reference conditions producing the same physiological response as under the conditions to be assessed (Jendritzky et al., 2012). The meteorological conditions of the reference environment refer to mean radiant temperature (Tmrt) that equals $\mathrm{Ta}$, $v$ of $0.5 \mathrm{~m} \mathrm{~s}^{-1}$ at $10 \mathrm{~m}$ height and vapour pressure (vp) of the ambient air that produces rh of $50 \%$, with the exception of high air temperatures $\left(>29^{\circ} \mathrm{C}\right)$ where reference vp is limited at $20 \mathrm{hPa}$ (Blazejczyk et al., 2013). Unlike other thermal indices where the modification of the rate of metabolic heat production is an option, in UTCI calculations it is a fixed representative value (135 $\mathrm{W} \mathrm{m}^{-2}$ ) of an average person walking at $4 \mathrm{~km} \mathrm{~h}^{-1}$ (Blazejczyk et al., 2013; Bröde et al., 2012b). Thus, the UTCI equivalent temperature of the considered environment is calculated based on the meteorological variables of Ta, vp, $v$ and Tmrt. The classification of UTCI in terms of human thermal stress is presented in Table 2 (Blazejczyk et al., 2013; Bröde et al., 2012b).

Since the runs of the multi-node physiological model can be a time-consuming process and in order to achieve significant savings in simulation time, a simplified approach was developed based on polynomial regression analysis (Bröde et al., 2012b). According to this option, the $\mathrm{UTCl}$ equivalent temperature is modeled by a six-degree polynomial regression function of Ta, Tmrt-Ta, vp and $v$, based on the results of numerous simulations with the multi-node physiological model (Bröde et al., 2012b). In the present analysis, the UTCl calculations were performed employing the software and the source code that is available on the official UTCI COST Action 730 website (UTCI, 2017) following the regression approach. The outcome is valid only when the input data range within the following bounds: $-50^{\circ} \mathrm{C} \leq \mathrm{Ta} \leq+50^{\circ} \mathrm{C},-30^{\circ} \mathrm{C} \leq \mathrm{Tmrt}$ $-\mathrm{Ta} \leq+70^{\circ} \mathrm{C}, 0.5 \mathrm{~m} \mathrm{~s}^{-1} \leq \mathrm{v} \leq 17 \mathrm{~m} \mathrm{~s}^{-1}$ and $5 \% \leq \mathrm{rh} \leq 100 \%$ (with $\mathrm{vp}<50 \mathrm{hPa}$ ). 
Table 2. Classification of UTCl equivalent temperature in terms of thermal stress (Blazejczyk et al., 2013; Bröde et al., 2012b)

\begin{tabular}{cc}
\hline UTCI $\left({ }^{\circ} \mathrm{C}\right)$ & Stress category \\
\hline above +46 & Extreme heat stress \\
\hline+38 to +46 & Very strong heat stress \\
\hline+32 to +38 & Strong heat stress \\
\hline+26 to +32 & Moderate heat stress \\
\hline+9 to +26 & No thermal stress \\
\hline+9 to 0 & Slight cold stress \\
\hline 0 to -13 & Moderate cold stress \\
\hline-13 to -27 & Strong cold stress \\
\hline-27 to -40 & Very strong cold stress \\
\hline below -40 & Extreme cold stress
\end{tabular}

As far as the UTCl computations are concerned, certain configurations on the input data should be made. The measuring height of $v$ at the stations AGK, GAL and MEN was lower than $10 \mathrm{~m}$ that is required, and therefore the following formula was applied in order to estimate $v$ at 10 $\mathrm{m}$ :

$$
\frac{v_{z_{1}}}{v_{z_{2}}}=\frac{\log \left(\frac{z_{1}}{0.01}\right)}{\log \left(\frac{z_{2}}{0.02}\right)}
$$

where $z$ is the measurement height of $v$. It is worth mentioning that the above formula is incorporated to the physiological model of UTCI in order to estimate $v$ at the body level (Bröde et al., 2012b).

The Tmrt parameter was determined employing the RayMan model that simulates short-wave and long-wave radiation fluxes (Matzarakis et al., 2007; Matzarakis et al., 2010). The input meteorological data into RayMan model was the Ta, rh, $v$ at $1.1 \mathrm{~m}$ height (body level) and sr. Furthermore, non-meteorological factors including the day of year, local time, time zone (UTC $+2 \mathrm{~h}$ ), longitude (Table 1), latitude (Table 1), altitude (Table 1), albedo, bowen-ratio and ratio of diffuse to global radiation was also imported. The albedo value was set at 0.15 . This value is more representative for Athens than the widely used value of 0.2 when albedo measurements are lacking (Psiloglou and Kambezidis, 2009). The bowen-ratio was assumed at 1.3 and the ratio of diffuse to global radiation at 0.2 .

In this study, $\mathrm{Ta}$ ranged between $-5.9^{\circ} \mathrm{C}$ and $44.2^{\circ} \mathrm{C}$, rh between $6.3 \%$ and $100 \%$, Tmrt $-\mathrm{Ta}$ between $-14.1^{\circ} \mathrm{C}$ and $54.8^{\circ} \mathrm{C}$ and $\mathrm{v}$ between $0 \mathrm{~m} \mathrm{~s}^{-1}$ and $16.6 \mathrm{~m} \mathrm{~s}^{-1}$. As already mentioned, the regression approach for UTCI calculations are only valid within certain bounds. It is obvious that only the lower bound of $\mathrm{v}$ is violated. In these cases the calculations were based on the lower bound of $v$ (Bröde et al., 2012b).

The UTCI values were computed based on the three-hour data of 0200, 0500,0800,1100,1400,1700, 2000, 2300 local standard time (LST). Thus, the daily UTCI was estimated as the arithmetic mean of the eight UTCI values. In the few cases where the number of $\mathrm{UTCl}$ values per day was less than eight, the day was excluded from the daily analysis so that the daily UTCI value was not biased. The results are presented on a seasonal basis in order to be more representative.

\subsection{Synoptic weather classification}

The patterns of the synoptic atmospheric circulation over the GAA in Greece were classified by employing the scheme developed by Kassomenos et al. (1998). More recently, the scheme became automated by Zagouras et al. (2013) with the aid of the graph theory. The classification was based on the geopotential height distribution at the isobaric level of $850 \mathrm{hPa}$. This level is preferred because the topographic effects are avoided and because it is representative of the lower troposphere. According to this clustering scheme, eight statistically distinct categories with respect to their thermodynamic features were detected. Each category presents a definite pattern concerning the position and orientation of synoptic systems, ridges and troughs. The eight categories with their description are presented as follows (Kassomenos et al., 1998):

- $\quad$ South-Westerly flow (SW): A trough is observed south-west of the examined area, resulting in south-westerly flow, being accompanied by advection of warm and moist air masses from Africa.

- $\quad$ North-Westerly flow (NW): When the trough has passed, a strong north-westerly flow is established over the GAA. This category is characterized by strong cold air advection from the north.

- Long-Wave trough (LW): A quasi stationary longwave trough prevails over Greece with its axis being positioned over the GAA. This category is associated with rainfall.

- Closed Low (CL): This cyclonic category is characterized by the presence of a closed low, being accompanied by intense winds, usually from the northern sector, and rainfall.

- Zonal flow (ZONAL): The circulation is almost zonal over the examined area, resulting in a prevailing westerly flow, being characterized by substantially lower intensity in the warm period of the year.

- Open Anticyclone (OA): A large-scale ridge dominates over the Greek area with weak variable winds, favouring the development of local flows over the examined area.

- Closed Anticyclone (CA): A closed anti-cyclone extends over the major Greek area. This category has similar characteristics to the previous one, but causes weaker winds or calm conditions over the GAA.

- Category High-Low (HL): A ridge is combined with a trough over the central-eastern Mediterranean basin, resulting in rather complicated regimes over the Athens basin. In the warm period, this 
category is mainly characterized by a strengthening of the pressure gradient and strong north-easterlies (the well-known "Etesians") that blow over the Aegean Sea.

In this study, the daily synoptic classification was applied to the GAA for the ten-year period from 2006 to 2015 by employing the daily composite charts of the geopotential height distribution at the isobaric level of $850 \mathrm{hPa}$ derived from the Earth System Research Laboratory of National Oceanic Atmospheric Administration (NOAA, 2017). The study period has 3652 days, and thus equal number of synoptic classifications was performed taking into consideration the position and orientation of synoptic systems, ridges and troughs at the isobaric level of 850 hPa.

The cross-classification technique was employed in order to depict the results. In particular, the cross-classification of thermal stress and synoptic categories is presented in two ways, as percent distribution of thermal stress classes per synoptic category and as weighted index. An aggregated weighted average is employed in order to reveal the impact of one number within the context of the total data. Index calculations were based on the formula:

$$
\text { Index }=\frac{(\text { cellvalue } \cdot \text { grand total })}{(\text { row total } \cdot \text { columntotal })}
$$

where the cell value is the percentage of thermal stress and synoptic category, the row total is the total percentage of the synoptic category, the column total is the total percentage of the thermal stress class and the grand total is $100 \%$. If all cell values are equal, each cell value will have a weighted index of 1 . Thus, index values greater than 1 indicate greater importance than other values in its synoptic category and thermal stress class. The opposite occurs for index values lower than 1 . It is worth mentioning that even if two cells have the same frequency of occurrence, they may have a different weighted index.

\section{Results and Discussion}

\subsection{Frequency of synoptic weather categories}

Figure 2 shows the relative frequency of occurrence of synoptic categories per season over the ten-year period. Certain synoptic categories indicate strong seasonality. In particular, HL and OA are observed more often during summer and autumn, whereas SW and CL occur more often during winter and spring. The categories LW and ZONAL are also noticed more often during winter and spring but with lower frequencies than SW and CL. The category NW displays limited seasonal pattern, while CA presents the lowest frequency of occurrence among the synoptic categories. Similar results were also obtained by Kassomenos et al. (2001), over the same study area but for a different time period and referring only to the seasons of summer and winter.

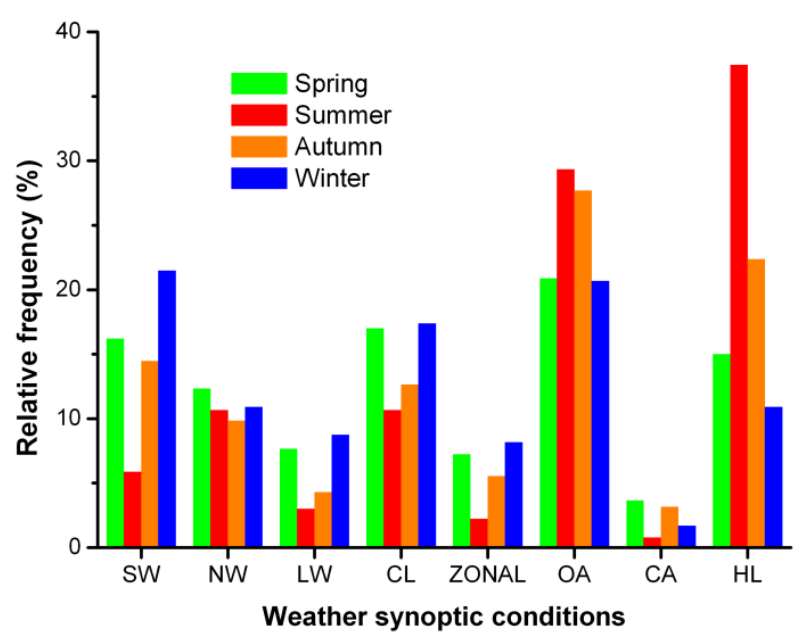

Figure 2. Relative frequency distribution of synoptic weather categories per season for the period 2006-2015

\subsection{Frequency of UTCI in terms of thermal stress}

The relative frequency distribution of three-hour UTCI values in terms of thermal stress is illustrated in Figure 3. The "extreme cold stress" class does not appear at any station, and thus the human thermal stress ranges between "extreme heat" and "very strong cold". This range of thermal stress is observed at all stations, with the exception of AGK, where the stress levels range between "very strong heat" and "strong cold". This is probably due to fact that this station is close to the sea and it is influenced by the quite high humidity levels and the development of sea breeze (Helmis et al., 1995; Helmis et al., 1997), an outcome that was also observed in a recent study (Katavoutas et al., 2015). Furthermore, the frequencies of "extreme heat stress" and "very strong cold stress" are extremely low, with percentages up to $0.09 \%$ (NOA) and $0.22 \%$ (MEN), respectively.

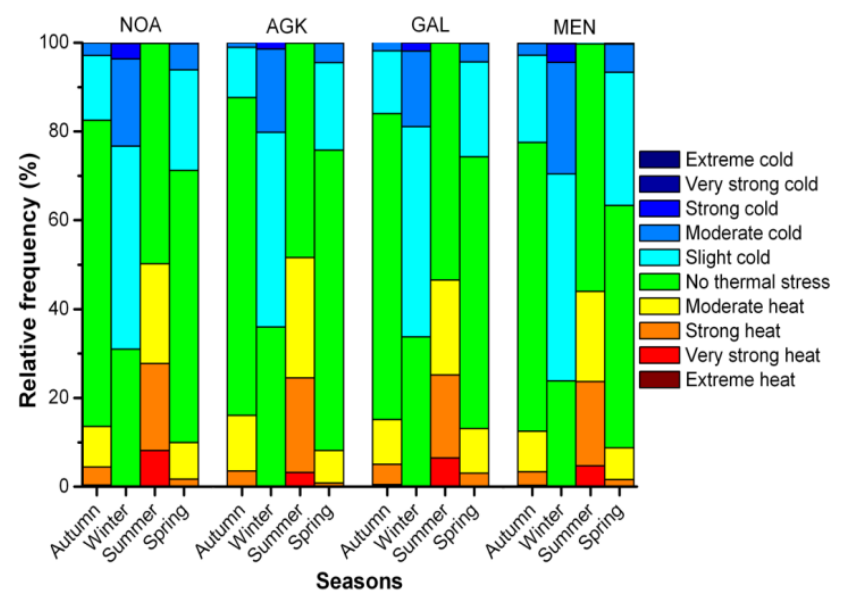

Figure 3. Relative frequency distribution of three-hour UTCI values classified in terms of thermal stress per station and season for the period 2006-2015

In winter, the "slight cold stress" class seems to dominate at all stations. This stress class is followed by the "no thermal stress" class for the stations located in the core of the city (NOA, GAL) and close to the sea (AGK), whereas this is not observed for the station at the north 
boundaries of the city (MEN), where the "moderate cold stress" class follows. Furthermore, the MEN station displays higher percentages at "strong cold stress" and "very strong cold stress" classes than the other stations because of its position, which is on the foot of mountain Parnitha and far from the core of the urban complex. In particular, the percentage of cold stress classes, regardless of the intensity level, reaches up to $76 \%$ at MEN, while it is clearly lower at the other stations and reaches up to $69 \%$ at NOA, $66 \%$ at GAL and $64 \%$ at AGK. The above observations are in accordance with the results obtained in recent studies showing that in terms of thermal sensation, the MEN station has exurban characteristics (Katavoutas et al., 2013; Katavoutas et al., 2015).

In summer, the percentage of heat stress classes, regardless of the intensity level, reaches up to $52 \%$ at AGK, $50 \%$ at NOA, $47 \%$ at GAL and $44 \%$ at MEN. The "extreme heat stress" class is observed at all stations, although at extremely low percentages (up to 0.09\%), with the exception of AGK. The stations at the urban core (NOA, GAL) present more hours with "very strong heat stress" than the other stations and the percentages are formed at $8 \%$ and $6 \%$, respectively. However, in the recent study of Katavoutas et al. (2015), higher frequencies were found at the heat stress classes, especially at the highest levels of stress, employing the thermal index PET. This is attributed to the great sensitivity of UTCI to $v$ and the less sensitivity of UTCI to Tmrt, compared to PET, and thus a breeze can partly attenuate the levels of heat stress that people perceive during hot spells (Błażejczyk et al., 2012; Provençal et al., 2016).

In the transitional seasons of spring and autumn, the "no thermal stress" class dominates at all stations. In autumn, the percentage of heat stress classes, regardless of the intensity level, is formed at $16 \%$ at AGK, $15 \%$ at GAL, $14 \%$ at NOA and $12 \%$ at MEN. On the other hand, the highest frequency of cold stress is observed at the station located at the north boundaries of the city (MEN, $22 \%$ ), while the lowest frequency is noted at the seashore station (AGK, $12 \%)$. In spring, the UTCI values are shifted lower, and thus the cold stress classes present higher frequencies than in autumn. Nevertheless, at all stations are observed hours with heat stress, regardless of the intensity level. This is more pronounced for the stations located in the urban core (GAL 13\%, NOA 10\%) as compared to the rest of the stations (AGK 8\%, MEN 9\%).

\subsection{Diurnal variation of UTCI per synoptic weather category}

The diurnal average UTCI per synoptic weather category in summer is presented in Figure 4. The lowest UTCI values are clearly observed on days with LW, followed by the days with NW, especially after 1100 LST. These days are found to display lower Ta values throughout the day and lower Tmrt values during nighttime than the days of the other synoptic categories. The last is explained by the fact that the Tmrt at nighttime is mainly affected by Ta due to the absence of solar radiation, in respect of the input meteorological parameters for the simulation of Tmrt. Furthermore, the LW category is a typical cyclonic pattern, a low pressure centre or a cold front, on the surface (Kassomenos et al., 1998). On the other hand, the NW category is typified by cold advection from the northwest or north (Kassomenos et al., 1998). The highest UTCI values are mainly noticed on days with CA and OA. By inspecting these days, higher Ta and Tmrt values are observed and in many cases lower rh values than those of the days of the other categories especially during daytime. Besides, in most of the cases, these two categories are associated with an anticyclonic circulation on the surface (Kassomenos et al., 1998) that favour the occurrence of hot spells (Katsoulis and Hatzianastassiou, 2005).

The range of UTCI is considerably wider during daytime than nighttime (Figure 4). This could be attributed to the lower $v$ values during nighttime, irrespectively of the synoptic category, and the fact that the Tmrt during nighttime is mainly affected by Ta due to the absence of solar radiation, in respect of the input meteorological parameters for the simulation of Tmrt. Thus, the average UTCI between 2000 and 0500 LST indicates "no thermal stress" for all the synoptic categories and all the stations. Between 0800 and 1700 LST, the average UTCI ranges between "moderate heat stress" and "strong heat stress", depending on the synoptic category. However, in the case of NOA station at 1400 LST, the average UTCI indicates three heat stress classes, "moderate", "strong" and "very strong", depending on the synoptic category. It is worth mentioning that even within the same thermal stress class, different UTCI values denote a difference in stress levels.

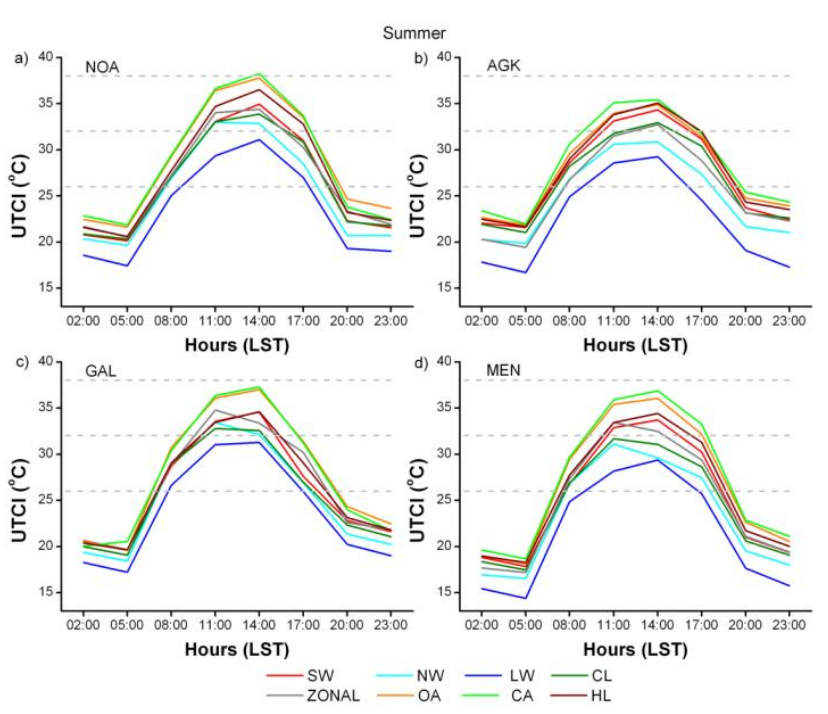

Figure 4. Diurnal variation of UTCI per synoptic weather category in summer for the stations (a) NOA, (b) AGK, (c) GAL, (d) MEN. Dashed lines indicate the UTCI bounds for different stress classes (see Table 2) 


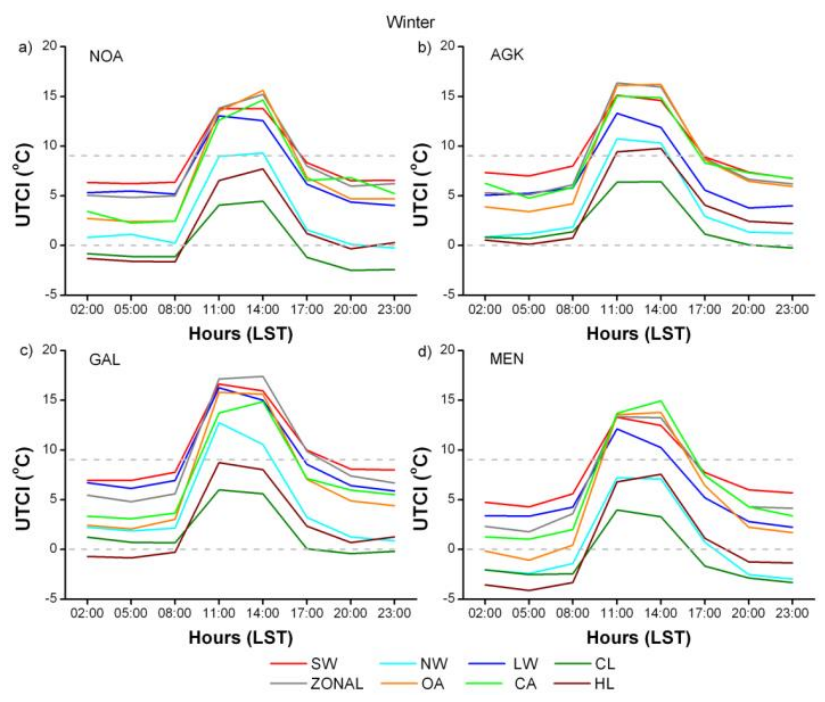

Figure 5. Diurnal variation of UTCI per synoptic weather category in winter for the stations (a) NOA, (b) AGK, (c) GAL, (d) MEN.

Dashed lines indicate the UTCI bounds for different stress classes (see Table 2)

Figure 5 presents the diurnal average UTCI per synoptic weather category in winter. The lowest UTCI values are observed on days with $\mathrm{CL}$ and $\mathrm{HL}$, followed by the days with NW. In particular, days with $\mathrm{CL}$ display the lowest UTCI values between 1100 and 2300 LST, followed by the days with $\mathrm{HL}$, while the opposite occurs from 0200 to 0800 LST. The days characterized by CL, HL and NW are found to display lower Ta and Tmrt values than the days of the other categories and quite high $v$ values. Furthermore, the days with NW present low rh values as compared to the values of the other categories, consistent with the strong cold air advection from the north or northwest that characterizes this category (Kassomenos et al., 1998). Although the impact of rh on cold stress at low and moderate Ta values is small, the impact of $v$ is significant (Bröde et al., 2012b). Therefore, the higher the observed $v$ values at low Ta values, the greater the cold stress and this effect is greater as Ta decreases. Moreover, the $\mathrm{UTCl}$ is very sensitive to the variations of $\mathrm{v}$ (Provençal et al., 2016). Besides, the $\mathrm{CL}$ category is a cyclonic synoptic type and associated with strong winds, rainfall and in general bad weather, while the $\mathrm{HL}$ category is associated with a prevailing, moderate or strong, northern flow (Kassomenos et al., 1998).

The highest UTCI values between 2000 and 0800 LST are noted on days with SW. By inspecting these days and hours, the Ta, rh and Tmrt values are revealed higher than those of the days of the other categories. These results are in agreement with this synoptic type that is associated with a south-westerly flow advecting warm and moist air masses from Africa. It is noteworthy that the SW category was found to be the most unfavorable, with the highest relative risk for mortality during the cold period in Athens (Kassomenos et al., 2001; Kassomenos et al., 2007). However, at 1100 and 1400 LST, the days with OA, ZONAL and CA present higher UTCI values than those with SW. This probably happens as a result of the clearer atmosphere that leads to higher sr values, and thus to higher Tmrt values.

The range of $\mathrm{UTCl}$ is wide both at daytime and at nighttime (Figure 5), although slightly reduced at night, in contrast to the summer (Figure 4). The average UTCI per hour displays two thermal stress classes, depending on the synoptic category. These stress classes are the "moderate cold stress" and the "slight cold stress" at nighttime, and the "slight cold stress" and the "no thermal stress" at daytime.
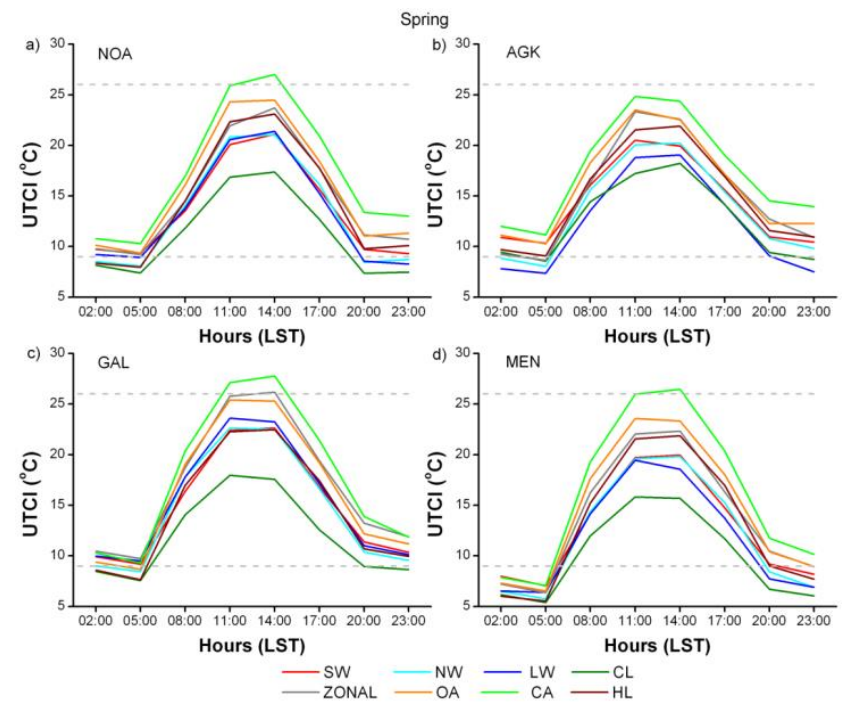

Figure 6. Diurnal variation of UTCI per synoptic weather category in spring for the stations (a) NOA, (b) AGK, (c) GAL, (d) MEN.

Dashed lines indicate the UTCI bounds for different stress classes (see Table 2)

In spring, the highest UTCl values are observed on days with CA, followed by the days characterized as OA and ZONAL (Figure 6). These days are found to display lower $v$ values and higher Ta and Tmrt values than the days of the others categories. As already mentioned, the CA, OA and ZONAL categories are mostly combined with an anticyclonic circulation on the surface (Kassomenos et al., 1998) and in general with fair weather conditions. On the other hand, the lowest UTCI values are clearly noted on days with CL, especially between 0800 and 2000 LST. An exception to this result occurs at the coastal AGK station, where the days with weather characterized by LW present the lowest UTCI values at nighttime. The days with $C L$, at NOA, GAL and MEN stations, are found to display higher $v$ values during the day and lower Ta values, especially at daytime, than the days of the other categories. On the other hand, at AGK station, the days with LW show higher $v$ values and in many cases lower Ta values than the days with CL. It is evident that the synoptic category which combines high $v$ values at low Ta values leads to lower UTCl values, and thus to greater cold stress or lower heat stress. Besides, the CL category is a pure cyclonic synoptic type being associated with strong winds, rainfall and in general bad weather, while the LW category is usually 
associated with a cyclonic pattern, a low pressure centre or a cold front, on the surface (Kassomenos et al., 1998).

The range of UTCI is wider at daytime than at nighttime in spring (Figure 6), which is also observed in summer (Figure 4). This could be attributed to the lower $v$ values during nighttime, irrespectively of the synoptic category, and the fact that the Tmrt at nighttime is mainly affected by Ta due to the absence of solar radiation, in respect of the input meteorological parameters for the simulation of Tmrt. The average UTCl displays "no thermal stress" for almost all the synoptic categories. However, "slight cold stress" is observed at nighttime, depending on the position of the station and the synoptic category. Furthermore, the average UTCI indicates "moderate heat stress" only for the days with CA, at 1100 and 1400 LST, with the exception of the coastal station (AGK).

The pattern in autumn (Figure 7) does not greatly differ from that observed in spring. Thus, the lowest UTCI values are noted on days with LW, followed by the days with $\mathrm{CL}$, especially between 0800 and 2300 LST. By inspecting these days and hours, lower Ta values and higher $v$ values are revealed than those of the days of the other categories. However, the synoptic category with the highest UTCI values is not so clear and distinct. The days characterized as OA present the highest UTCI values, especially at 1100 and 1400 LST, because of the high Ta and Tmrt values and the low $v$ values. On the contrary, high $\mathrm{UTCl}$ values are observed on days with SW at nighttime due to the low $v$ values and the quite high $r h$ values. The range of $\mathrm{UTCl}$ is not so wide at daytime, although wider than at nighttime.

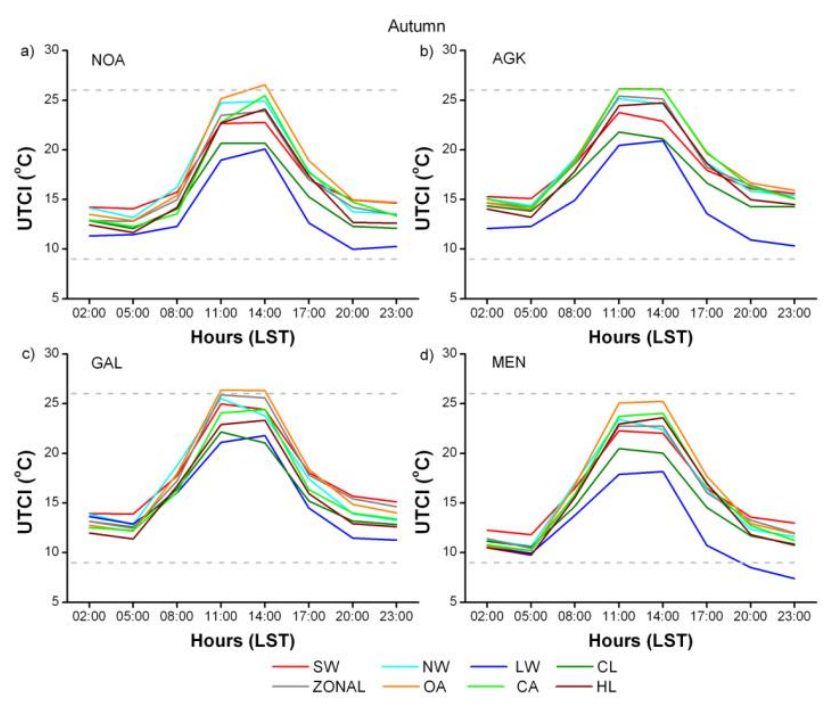

Figure 7. Diurnal variation of UTCI per synoptic weather category in autumn for the stations (a) NOA, (b) AGK, (c) GAL, (d) MEN.

Dashed lines indicate the UTCI bounds for different stress classes (see Table 2)

A visual inspection of the results per season reveals that the position of the station affects the diurnal average UTCI for the same synoptic category. In particular, for the station located at the north boundaries of the city (MEN), lower average UTCl values are observed compared to the other stations for the same synoptic category at nighttime. This is not so apparent at daytime. On the other hand, the results for the seashore station (AGK) show relatively smaller diurnal variation of average UTCI per synoptic category than the other stations.

As already mentioned, Kassomenos et al. (2001, 2007) found that the SW category is the most unfavorable, with the highest relative risk for mortality during the cold and the warm period of the year in Athens. Epidemiological studies have shown that elderly people, young children and infants have increased risk for mortality from high ambient temperature (Basu, 2009), and thus these vulnerable groups are most affected by thermal stress. However, in the present analysis the thermal stress levels were estimated based on UTCI thermal index, which refers to an "average" healthy individual.

\subsection{Cross-classification of thermal stress and synoptic categories}

The cross-classification of thermal stress and synoptic categories is presented in Tables 3 and 4 for the summer and the winter season, respectively. The classification of thermal stress is based on daily UTCI values. On each cell of the tables, the first entry presents the percentage of thermal stress class for the synoptic category and the second entry, within the parenthesis, shows the weighted index. As far as the frequency distribution is concerned, the "moderate heat stress" class seems to dominate in all synoptic categories during summer, with the exception of days with NW and LW, where the "no thermal stress" class is noticed more often (Table 3 ). This is observed in all stations located in the core of the city (NOA, GAL) and close to the sea (AGK), although quantitative differences are noted, but it is not observed for the station located at the north boundaries of the city (MEN). In this station, the "moderate heat stress" class dominates only during days with OA and CA. This is probably due to the position of MEN station, which is far from the core of the urban complex, and thus it is less affected by urban warming. Furthermore, the frequencies of the synoptic categories $\mathrm{OA}$ and $\mathrm{CA}$ at the higher thermal stress class is lower in AGK as compared to the station located in the city center (NOA) due to the development of sea breeze (Helmis et al., 1995; Helmis et al., 1997), which acts to reduce the temperature in the southern suburbs during daytime.

Regarding the frequency distribution in winter, the days with NW, CL and $\mathrm{HL}$ are mainly distributed between the classes of "slight cold stress" and "moderate cold stress" (Table 4). On the other hand, the days of the remaining synoptic categories are mainly distributed between the classes of "no thermal stress" and "slight cold stress". An exception to this is observed in MEN station, where quite high frequencies in the "slight cold stress" and the "moderate cold stress" classes reveal in all synoptic categories. As far as the weighted index is concerned, the SW synoptic category has clearly more impact on the "no thermal stress" class than on the classes of cold stress in winter (Table 4) and differs from the other cyclonic types. 
The opposite occurs for the synoptic categories NW, CL and HL. The categories OA and CA account principally for the classes "no thermal stress" and "slight cold stress" than on the highest levels of cold stress. The LW category has actually more impact on the "no thermal stress" class only at the station located in the urban core (GAL). The ZONAL category displays ambiguous weighted index results for the stations and for the thermal stress classes as well. In particular, this synoptic category presents higher impact on the "no thermal stress" class than on the classes of cold stress only at the stations NOA and MEN. On the other hand, the opposing classes "strong cold stress" and "no thermal stress" have the greatest contribution to the synoptic category ZONAL at the stations AGK and GAL.

Table 3. Cross-classification of thermal stress and synoptic categories based on daily UTCI values in summer. Percent distribution of synoptic category and weighted index are displayed on each cell

\begin{tabular}{|c|c|c|c|c|}
\hline \multirow{3}{*}{ Station } & \multirow{3}{*}{$\begin{array}{l}\text { Synoptic } \\
\text { category }\end{array}$} & \multicolumn{3}{|c|}{ Thermal stress classes } \\
\hline & & Strong heat & Moderate heat & No thermal stress \\
\hline & & $\%$ (Index) & $\%$ (Index) & $\%$ (Index) \\
\hline \multirow{8}{*}{ NOA } & SW & $0(0.00)$ & $62(1.03)$ & $38(1.14)$ \\
\hline & NW & $0(0.00)$ & $39(0.65)$ & $61(1.83)$ \\
\hline & LW & $0(0.00)$ & $35(0.58)$ & $65(1.95)$ \\
\hline & $\mathrm{CL}$ & $3(0.52)$ & $54(0.90)$ & $43(1.27)$ \\
\hline & ZONAL & $6(0.92)$ & $76(1.27)$ & $18(0.53)$ \\
\hline & $\mathrm{OA}$ & $11(1.78)$ & $67(1.11)$ & $22(0.65)$ \\
\hline & CA & $17(2.60)$ & $67(1.11)$ & $16(0.50)$ \\
\hline & $\mathrm{HL}$ & $7(1.04)$ & $63(1.05)$ & $30(0.90)$ \\
\hline \multirow{8}{*}{ GAL } & SW & $0(0.00)$ & $55(0.97)$ & $45(1.10)$ \\
\hline & NW & $0(0.00)$ & $39(0.68)$ & $61(1.49)$ \\
\hline & LW & $0(0.00)$ & $30(0.53)$ & $70(1.71)$ \\
\hline & $\mathrm{CL}$ & $0(0.00)$ & $49(0.87)$ & $51(1.24)$ \\
\hline & ZONAL & $5(2.05)$ & $60(1.07)$ & $35(0.85)$ \\
\hline & $\mathrm{OA}$ & $5(2.01)$ & $67(1.18)$ & $28(0.69)$ \\
\hline & $\mathrm{CA}$ & $0(0.00)$ & $86(1.52)$ & $14(0.35)$ \\
\hline & $\mathrm{HL}$ & $2(0.97)$ & $57(1.01)$ & $41(0.99)$ \\
\hline \multirow{8}{*}{ AGK } & SW & $0(0.00)$ & $74(1.14)$ & $26(0.83)$ \\
\hline & NW & $0(0.00)$ & $34(0.53)$ & $66(2.10)$ \\
\hline & LW & $0(0.00)$ & $12(0.19)$ & $88(2.79)$ \\
\hline & $\mathrm{CL}$ & $2(0.58)$ & $63(0.98)$ & $35(1.10)$ \\
\hline & ZONAL & $0(0.00)$ & $50(0.77)$ & $50(1.59)$ \\
\hline & OA & $7(1.77)$ & $70(1.08)$ & $23(0.73)$ \\
\hline & $\mathrm{CA}$ & $15(3.83)$ & $71(1.10)$ & $14(0.46)$ \\
\hline & $\mathrm{HL}$ & $4(1.00)$ & $72(1.11)$ & $24(0.76)$ \\
\hline \multirow{8}{*}{ MEN } & SW & $0(0.00)$ & $42(0.90)$ & $58(1.11)$ \\
\hline & NW & $0(0.00)$ & $20(0.43)$ & $80(1.53)$ \\
\hline & LW & $0(0.00)$ & $7(0.16)$ & $93(1.76)$ \\
\hline & $\mathrm{CL}$ & $0(0.00)$ & $41(0.88)$ & $59(1.13)$ \\
\hline & ZONAL & $0(0.00)$ & $30(0.65)$ & $70(1.33)$ \\
\hline & OA & $3(2.17)$ & $59(1.29)$ & $38(0.72)$ \\
\hline & $\mathrm{CA}$ & $0(0.00)$ & $71(1.55)$ & $29(0.54)$ \\
\hline & $\mathrm{HL}$ & $1(0.97)$ & 49 (1.07) & $50(0.94)$ \\
\hline
\end{tabular}

\section{Conclusions}

The present study investigates the thermal stress levels based on the recently developed Universal Thermal Climate Index (UTCI) with respect to the synoptic scale circulation over the metropolitan city of Athens. The patterns of the synoptic atmospheric circulation were classified in eight distinct categories based on a clustering scheme. The three-hour UTCI equivalent temperatures were calculated in four sites of the urban complex for a ten-year period.
The diurnal variation during summer reveals lower UTCI values on days that are associated with a cyclonic pattern or a cold advection from the northwest or north compared to the other synoptic categories. On the other hand, the days with an anticyclonic pattern show the highest UTCI values. During winter, the days that are associated with a pure cyclonic pattern, a prevailing northern flow and a strong cold air advection from the northwest or north display lower UTCI values than the days of the other synoptic categories. During nighttime, higher UTCI values are observed on days with south- 
westerly flow, as compared to the other categories, being associated with advection of warm and moist air masses from Africa. However, this finding is not noticed around midday when anticyclonic patterns and westerly flow show higher UTCI values than south-westerly flow.

Table 4. Cross-classification of thermal stress and synoptic categories based on daily UTCI values in winter. Percent distribution of synoptic category and weighted index are displayed on each cell

\begin{tabular}{|c|c|c|c|c|c|c|}
\hline \multirow{3}{*}{ Station } & \multirow{3}{*}{$\begin{array}{l}\text { Synoptic } \\
\text { category }\end{array}$} & \multicolumn{5}{|c|}{ Thermal stress classes } \\
\hline & & $\begin{array}{l}\text { No thermal } \\
\text { stress }\end{array}$ & $\begin{array}{l}\text { Slight } \\
\text { cold }\end{array}$ & Moderate cold & $\begin{array}{c}\text { Strong } \\
\text { cold }\end{array}$ & Very strong cold \\
\hline & & $\%$ (Index) & $\%$ (Index) & $\%$ (Index) & $\%$ (Index) & $\%$ (Index) \\
\hline \multirow{8}{*}{ NOA } & SW & $51(1.59)$ & $46(0.95)$ & $2(0.10)$ & $1(0.25)$ & $0(0.00)$ \\
\hline & NW & $14(0.43)$ & $58(1.16)$ & $27(1.69)$ & $1(0.48)$ & $0(0.00)$ \\
\hline & LW & $31(0.98)$ & $64(1.28)$ & $5(0.32)$ & $0(0.00)$ & $0(0.00)$ \\
\hline & $\mathrm{CL}$ & $8(0.27)$ & $52(1.04)$ & $33(2.05)$ & $7(2.99)$ & $0(0.00)$ \\
\hline & ZONAL & 51 (1.59) & $45(0.91)$ & $3(0.17)$ & $1(0.64)$ & $0(0.00)$ \\
\hline & OA & $40(1.26)$ & $50(0.99)$ & $9(0.58)$ & $1(0.50)$ & $0(0.00)$ \\
\hline & CA & $33(1.05)$ & $60(1.21)$ & $7(0.41)$ & $0(0.00)$ & $0(0.00)$ \\
\hline & $\mathrm{HL}$ & $22(0.67)$ & $34(0.69)$ & $40(2.45)$ & $4(1.97)$ & $0(0.00)$ \\
\hline \multirow{8}{*}{ GAL } & SW & $69(1.65)$ & $29(0.68)$ & $2(0.11)$ & $0(0.00)$ & $0(0.00)$ \\
\hline & NW & $21(0.50)$ & $60(1.42)$ & $19(1.30)$ & $0(0.00)$ & $0(0.00)$ \\
\hline & LW & $61(1.44)$ & $36(0.83)$ & $4(0.27)$ & $0(0.00)$ & $0(0.00)$ \\
\hline & $\mathrm{CL}$ & $13(0.30)$ & $55(1.28)$ & $29(2.01)$ & $4(4.32)$ & $0(0.00)$ \\
\hline & ZONAL & $63(1.49)$ & $35(0.81)$ & $1(0.10)$ & $1(1.52)$ & $0(0.00)$ \\
\hline & $\mathrm{OA}$ & $43(1.03)$ & $46(1.07)$ & $11(0.77)$ & $0(0.00)$ & $0(0.00)$ \\
\hline & $\mathrm{CA}$ & 47 (1.11) & 47 (1.09) & $7(0.46)$ & $0(0.00)$ & $0(0.00)$ \\
\hline & $\mathrm{HL}$ & $23(0.55)$ & $38(0.89)$ & $38(2.63)$ & 1 (1.15) & $0(0.00)$ \\
\hline \multirow{8}{*}{ AGK } & SW & $61(1.51)$ & $37(0.85)$ & $2(0.15)$ & $0(0.00)$ & $0(0.00)$ \\
\hline & NW & $23(0.57)$ & $51(1.18)$ & $25(1.63)$ & $1(1.31)$ & $0(0.00)$ \\
\hline & LW & $31(0.76)$ & $62(1.44)$ & $7(0.45)$ & $0(0.00)$ & $0(0.00)$ \\
\hline & $\mathrm{CL}$ & $15(0.37)$ & $48(1.11)$ & $34(2.22)$ & $3(3.27)$ & $0(0.00)$ \\
\hline & ZONAL & $57(1.38)$ & $41(0.95)$ & $1(0.10)$ & $1(1.77)$ & $0(0.00)$ \\
\hline & OA & $54(1.34)$ & $37(0.85)$ & $9(0.56)$ & $0(0.00)$ & $0(0.00)$ \\
\hline & CA & $53(1.32)$ & $40(0.92)$ & $7(0.44)$ & $0(0.00)$ & $0(0.00)$ \\
\hline & $\mathrm{HL}$ & $27(0.66)$ & $40(0.93)$ & $32(2.08)$ & $1(1.28)$ & $0(0.00)$ \\
\hline \multirow{8}{*}{ MEN } & SW & $34(1.83)$ & 64 (1.07) & $2(0.11)$ & $0(0.00)$ & $0(0.00)$ \\
\hline & NW & $7(0.40)$ & $50(0.83)$ & $40(2.00)$ & $2(1.14)$ & $1(9.13)$ \\
\hline & LW & $20(1.08)$ & 75 (1.25) & $5(0.27)$ & $0(0.00)$ & $0(0.00)$ \\
\hline & $\mathrm{CL}$ & $7(0.36)$ & $47(0.79)$ & $39(1.97)$ & $7(3.96)$ & $0(0.00)$ \\
\hline & ZONAL & $27(1.44)$ & $68(1.13)$ & $4(0.21)$ & $1(0.76)$ & $0(0.00)$ \\
\hline & $O A$ & $18(0.96)$ & 70 (1.17) & $12(0.61)$ & $0(0.00)$ & $0(0.00)$ \\
\hline & CA & $27(1.46)$ & $67(1.11)$ & $6(0.34)$ & $0(0.00)$ & $0(0.00)$ \\
\hline & $\mathrm{HL}$ & $11(0.58)$ & $43(0.72)$ & $44(2.24)$ & $2(1.15)$ & $0(0.00)$ \\
\hline
\end{tabular}

Another worthy finding is that the range of UTCI between the synoptic categories with the upper and lower values is considerably wider during daytime than nighttime in summer. This is also observed in the transitional seasons of spring and autumn, but to a lesser extent. On the contrary, it is not observed during winter, when the range of $\mathrm{UTCl}$ is equally wide both during daytime and nighttime.

The analysis also shows that the position of the station affects the diurnal variation of UTCl and the frequency distribution of thermal stress classes for the same synoptic category. Overall, although the synoptic categories compose distinct meteorological conditions, rather complicated regimes are often generated, including local flows over the study area. Besides, the employed UTCI thermal index is based on a greater number of meteorological variables, i.e., air temperature, vapor pressure, wind speed and solar radiation, which act synergistically to determine the thermal stress levels.

\section{Acknowledgments}

This research was fully supported and funded by the Project "IKY Fellowships of Excellence for Postgraduate Studies in Greece Siemens Program". The authors would like to thank Prof. Dr. Andreas Matzarakis for the provision of RayMan model and also the National Observatory of Athens and the National Technical University of Athens for the provision of the meteorological data. 


\section{References}

Bartoszek K., Wereski S., Krzyżewska A. and Dobek M. (2017), The influence of atmospheric circulation on bioclimatic conditions in Lublin (Poland), Bulletin of Geography, Physical Geography Series, 12, 41-49.

Bartzokas A., Lolis C.J., Kassomenos P.A. and McGregor G.R. (2013), Climatic characteristics of summer human thermal discomfort in Athens and its connection to atmospheric circulation, Natural Hazards and Earth System Sciences, 13, 3271-3279.

Basarin B., Lukić T. and Matzarakis A. (2016), Quantification and assessment of heat and cold waves in Novi Sad, Northern Serbia, International Journal of Biometeorology, 60, 139-150.

Basu R. (2009), High ambient temperature and mortality: A review of epidemiologic studies from 2001 to 2008, Environmental Health, 8, 40.

Blazejczyk K., Epstein Y., Jendritzky G., Staiger H. and Tinz B. (2012), Comparison of UTCl to selected thermal indices, International Journal of Biometeorology, 56, 515-535.

Błażejczyk K., Jendritzky G., Bröde P., Fiala D., Havenith G., Epstein Y., Psikuta A. and Kampmann B. (2013), An introduction to the Universal Thermal Climate Index (UTCI), Geographia Polonica, 86, 5-10.

Bröde P., Krüger E.L., Rossi F.A. and Fiala D. (2012a), Predicting urban outdoor thermal comfort by the Universal Thermal Climate Index UTCI-a case study in Southern Brazil, International Journal of Biometeorology, 56, 471-480.

Bröde P., Fiala D., Błażejczyk K., Holmér I., Jendritzky G., Kampmann B., Tinz B. and Havenith G. (2012b), Deriving the operational procedure for the Universal Thermal Climate Index (UTCI), International Journal of Biometeorology, 56, 481-494.

De Freitas C.R. and Grigorieva E.A. (2017), A comparison and appraisal of a comprehensive range of human thermal climate indices, International Journal of Biometeorology, 61, 487-512.

Fiala D., Havenith G., Bröde P., Kampmann B. and Jendritzky G. (2012), UTCI-Fiala multi-node model of human heat transfer and temperature regulation, International Journal of Biometeorology, 56, 429-441.

Havenith G., Fiala D., Błazejczyk K., Richards M., Bröde P., Holmér I., Rintamaki H., Benshabat Y. and Jendritzky G. (2012), The UTCl-clothing model, International Journal of Biometeorology, 56, 461-470.

Helmis C.G., Papadopoulos K.H., Kalogiros J.A., Soilemes A.T. and Asimakopoulos D.N. (1995), Influence of background flow on evolution of Saronic Gulf sea breeze, Atmospheric Environment, 29, 3689-3701.

Helmis C.G., Asimakopoulos D.N., Papadopoulos K.H., Kalogiros J.A., Kassomenos P., Papageorgas P.G. and Blikas S. (1997), Air mass exchange between the Athens Basin and the Messogia Plain of Attika, Greece, Atmospheric Environment, 31, 3833-3849.

Jendritzky G., de Dear R. and Havenith G. (2012), UTCl-Why another thermal index?, International Journal of Biometeorology, 56, 421-428.

Kassomenos P., Flocas H.A., Lykoudis S. and Petrakis M. (1998), Analysis of Mesoscale Patterns in Relation to Synoptic Conditions over an Urban Mediterranean Basin, Theoretical and Applied Climatology, 59, 215-229.
Kassomenos P., Gryparis A., Samoli E., Katsouyanni K., Lykoudis S. and Flocas H.A. (2001), Atmospheric circulation types and daily mortality in Athens, Greece, Environmental Health Perspectives, 109, 591-596.

Kassomenos P.A., Sindosi O.A. and Lolis C.J. (2003), Seasonal variation of the circulation types occurring over southern Greece: A 50-year study, Climate Research, 24, 33-46.

Kassomenos P.A., Gryparis A. and Katsouyanni K. (2007), On the association between daily mortality and air mass types in Athens, Greece during winter and summer, International Journal of Biometeorology, 51, 315-322.

Katavoutas G., Georgiou G.K., Asimakopoulos D.N. and Theoharatos G. (2013), Heat island and thermal bioclimate in Athens, Greece, In: Advances in Meteorology, Climatology and Atmospheric Physics, Helmis C.G., Nastos P.T. (Eds.), Springer, Germany.

Katavoutas G., Georgiou G.K. and Asimakopoulos D.N. (2015), Studying the urban thermal environment under a humanbiometeorological point of view: The case of a large coastal metropolitan city, Athens, Atmospheric Research, 152, 8292.

Katsoulis B.D. and Hatzianastassiou N. (2005), Analysis of hot spell characteristics in the Greek region, Climate Research, 28, 229-241.

Kolendowicz L., Półrolniczak M., Szyga-Pluta K. and Bednorz E. (2017), Human-biometeorological conditions in the southern Baltic coast based on the universal thermal climate index (UTCI), Theoretical and Applied Climatology, https://doi.org/10.1007/s00704-017-2279-2.

Lai P.C., Choi C.C., Wong P.P., Thach T.Q., Wong M.S., Cheng W., Kramer A. and Wong C.M. (2016), Spatial analytical methods for deriving a historical map of physiological equivalent temperature of Hong Kong, Building and Environment, 99, 22-28.

Matzarakis A. and Nastos P.T. (2011), Human-biometeorological assessment of heat waves in Athens, Theoretical and Applied Climatology, 105, 99-106.

Matzarakis A., Rutz F. and Mayer H. (2007), Modelling radiation fluxes in simple and complex environments-application of the RayMan model, International Journal of Biometeorology, 51, 323-334.

Matzarakis A., Rutz F. and Mayer H. (2010), Modelling radiation fluxes in simple and complex environments: basics of the RayMan model, International Journal of Biometeorology, 54, 131-139.

Mavrakis A., Spanou A., Pantavou K., Katavoutas G., Theoharatos G., Christides A. and Verouti E. (2012), Biometeorological and air quality assessment in an industrialized area of eastern Mediterranean: the Thriassion Plain, Greece, International Journal of Biometerology, 56, 737-747.

Mihalakakou G., Flocas H.A., Santamouris M. and Helmis C.G. (2002), Application of neural networks to the simulation of the heat island over Athens, Greece, using synoptic types as a predictor, Journal of Applied Meteorology, 41, 519-527.

Nastos P.T. and Matzarakis A. (2012), The effect of air temperature and human thermal indices on mortality in Athens, Theoretical and Applied Climatology, 108, 591-599.

NOAA (2017), Earth System Research Laboratory of National Oceanic Atmospheric Administration, Available online: https://www.esrl.noaa.gov/psd/data/composites/day/ (accessed on 15 June 2017). 
Petrakakis M.J., Kelessis A.G., Flocas H.A., Zoumakis N.M., Helmis C.G. and Tsougas M.A. (2006), Meteorological conditions during air pollution episodes in Thessaloniki, Greece, Fresenius Environmental Bulletin, 15, 916-922.

Provençal S., Bergeron O., Leduc R. and Barrette N. (2016), Thermal comfort in Quebec City, Canada: sensitivity analysis of the UTCl and other popular thermal comfort indices in a mid-latitude continental city, International Journal of Biometeorology, 60, 591-603.

Psiloglou B.E. and Kambezidis H.D. (2009) Estimation of the ground albedo for the Athens area, Greece, Journal for Atmospheric and Solar-Terrestrial Physics, 71, 943-954.

Rozbicka K. and Rozbicki T. (2017), Variability of UTCI index in South Warsaw depending on atmospheric circulation, Theoretical and Applied Climatology, 133, 511-520.

Theoharatos G., Pantavou K., Mavrakis A., Spanou A., Katavoutas G., Efstathiou P., Mpekas P. and Asimakopoulos D. (2010), Heat waves observed in 2007 in Athens, Greece: synoptic conditions, bioclimatological assessment, air quality levels and health effects, Environmental Research, 110, 152-161.

Tyrlis E. and Lelieveld J. (2013), Climatology and dynamics of the summer Etesian winds over the eastern Mediterranean, Journal of the Atmospheric Sciences, 70, 3374-3396.

UTCI (2017), Universal Thermal Climate Index, Available online: http://www.utci.org (accessed on 11 July 2017).

Urban A. and Kyselý J. (2014), Comparison of UTCI with other thermal indices in the assessment of heat and cold effects on cardiovascular mortality in the Czech Republic, International Journal of Environmental Research and Public Health, 11, 952-967.

Zagouras A., Argiriou A.A., Economou G., Fotopoulos S. and Flocas H.A. (2013), Weather maps classification over Greek domain based on isobaric line patterns, Theoretical and Applied Climatology, 114, 691-704. 